\title{
Applications (Fun and Practical) of FIB Nano-Deposition and Nano-Machining
}

Michael W. Phaneuf

Fibics Incorporated, 556 Booth St. Suite 200 Ottawa, Ontario Canada K1A 0G1 (info@fibics.com)

The use of focused ion beam (FIB) systems for nano- and micromachining is well documented [1-3], as is the FIB's capability for deposition of metals and insulators [4, references contained in 5]. FIB has been successful in direct-write lithography applications, and even the engraving of half-tone photographic images [6]. FIB depositions of silicon oxide can be made to tailor the index of refraction [7] resulting in depositions that run from transparent to opaque for visible light.

This presentation will discuss the combined use of FIB deposition of tungsten and silicon oxide and their subsequent FIB machining to form "nanostructures" with at least one dimension on the submicron scale (Figure 1). With some effort and creativity, FIB depositions can be made to span free space (arches and more complex structures) or to form structures with aspect ratios of 50:1 or greater. "Nano-tools" can be fabricated such as drill-bits and chisels (Figure 2). FIB machining has already been demonstrated to improve probes used in atomic force microscopy (AFM) and nearfield scanning optical microscopy (NSOM) [8, 9]; combining these approaches with FIB nanodeposition and nano-machining will permit the production of NSOM tips with near-AFM spatial resolution as well as the already achieved improved optical resolution (Figure 3).

FIB "tungsten" depositions have been measured by quantitative electron probe microanalysis (EPMA) to contain approximately $5 \mathrm{wt} . \% \mathrm{C}, 15 \mathrm{wt} \% \mathrm{Ga}$ and $80 \mathrm{wt} . \% \mathrm{~W}$, with resistivity better than $160 \mu \mathrm{O} \cdot \mathrm{cm}$. The effect of annealing on these parameters will be presented [10]

\section{References}

1. M.J. Vasile, R. Nassa, J. Xie, H. Guo, Micron 30 (1999) 235-244.

2. V.P. Dravid, Microsc. Microanal. 7 (Suppl. 2: Proceedings) (2001) 926-927.

3. V.P. Dravid, S. Kim and L.N. Brewer, Microsc. Microanal. 6 (Suppl. 2: Proceedings) (2001) 504-505.

4. D.Stewart, A. Doyle and J. D. Casey, SPIE 2437 (1995) 276-283.

5. M.W. Phaneuf, Micron, 20, (1999) 277-288.

6. L.E. Erickson, H.G. Champion, J.W. Fraser, R.J. Hussey, P. Schmuki and C. Porco J. Vac. Sci. Technol. B 15 (6), 2358-2361 (1997).

7. Private conversations / Unpublished work of Micrion Corporation (now FEI Company). Thanks to Drs. Ganesh Sundaram, Neil Bassom and J. David Casey Jr.

8. R.S. Taylor, J. Li, M. Phaneuf, Monologue of the 2nd Asia-Pacific Workshop on Near-Field Optics, Beijing, 1999.

9. S. Pilevar, K. Edinger, W. Atia, I. Smolyaninov, C.Davis, Appl. Phys. Lett. 72 (1998) 31333135.

10. Fibics thanks Dr. Rod Packwood, Emeritus EMPA Scientist, Materials Technology Laboratory, Natural Resources Canada for the EMPA of our W depositions and useful discussions, and Dr. Rod Taylor, Institute for Microstructural Sciences, National Research Council of Canada for collaborative work on improving NSOM probe tips. 


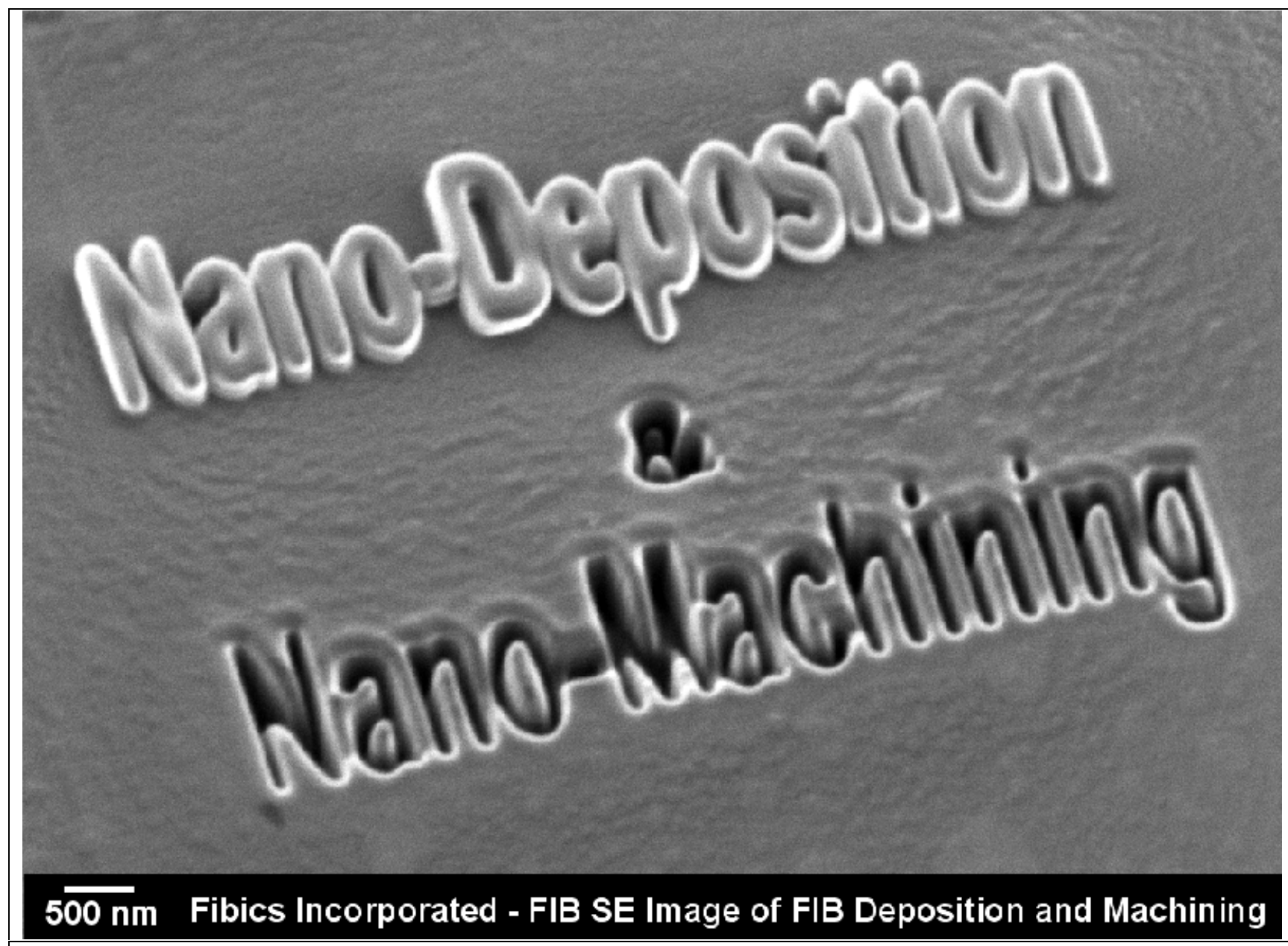

FIG. 1. FIB deposition can produce features $200 \mathrm{~nm}$ or less in thickness. FIB milling can produce even finer results. This structure required approximately 30 minutes of FIB time to produce.

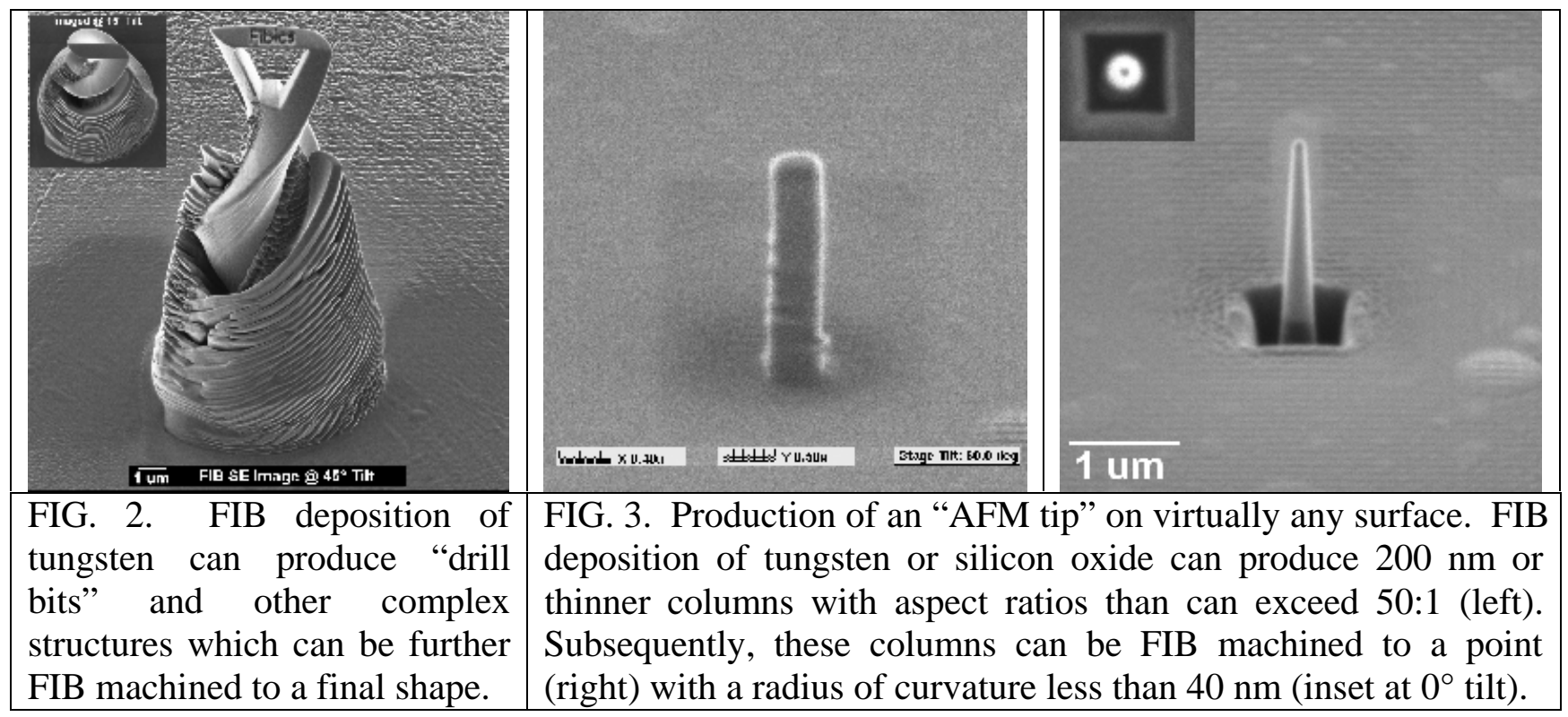

